\title{
Psychiatric and Neuropsychological Features of Pallister-Hall Syndrome. A Mini Review and Case Report
}

\author{
Pertega-Gomes $\mathrm{A}^{1}$, Gonçalves $\mathrm{E}^{2}$, Moniz $\mathbf{M}^{3}$, Nascimento $\mathrm{S}^{1}$ and Baptista $\mathrm{S}^{1}$ \\ ${ }^{1}$ Centro Hospitalar Universitario do Algarve, Chua \\ ${ }^{2} \mathrm{PhD}$ in Psychology and MD (psychiatrist), Chua
}

${ }^{3} \mathrm{PhD}$ in Psychology and clinical psychologist, Chua

Submission: September 15, 2017; Published: October 26, 2017

*Corresponding author: Alexandre Gomes, Centro Hospitalar Universitario do Algarve, Chua, Email: alexandre.pertega.gomes@gmail.com

\section{Introduction}

\section{Summary}

Pallister-Hall syndrome is a rare polimal formative syndrome, first described in 1980. The core features include central polydactyly and hypothalamic hamartoma, which can be associated with several additional anomalies. Originally thought to be lethal in the perinatal period, it was more recently recognized that milder phenotypic forms of the syndrome exist, in individuals with a normal lifespan. The genetic cause is known to be a mutation in the GLI3 gene. The phenotypic variability of this syndrome is not well characterized, particularly regarding the psychiatric and neuropsychological features of the disorder. To date, few studies exist on the topic and no stereotypic patterns have been uncovered.

The recognition of particular psychiatric and neuropsychological aspects associated with genetic syndromes is a powerful tool to shed light on the genetic contributions to mental illness. We hereby report the case of a 33 years old Caucasian male with clinical diagnosis of Pallister-Hall syndrome, refractory seizures and recurrent psychosis, detailing on the psychiatric history and performance profile in a battery of neuropsychological tests, both in inward and outpatient settings.

\section{Background}

Pallister-Hall syndrome was described for the first time in 1980 by Judith [1], originally characterized by congenital hypothalamic hamartoblastoma, hypopituitarism, imperforated anus, postaxial polydactyly, and various visceral anomalies, and thought to be uniformly lethal in the perinatal period [2]. Since their first reports, additional cases were published, revealing the existence of milder phenotypic forms, including cases of asymptomatic individuals with a normal life expectancy $[3,4]$.
The syndrome has a rare incidence and is inherited as an autosomal dominant mutation with variable expressivity, even though many cases described are due to spontaneous mutations [5], as is the case of our patient. Specifically, there's a frame shift mutation of the GLI3 gene (chromosomal location 7p13), that codes for a zinc finger domain DNA-binding protein that functions in the sonic hedgehog pathway, widely expressed during embryogenesis and known to be involved in the developmental morphogenesis of many organ systems, including the CNS [6,7]. Further histological characterization of the hypothalamic lesions in older probands revealed tumours with a more mature appearance and benign clinical course, and the core feature of the syndrome is now assigned to hypothalamic hamartomas, characteristically associated with polydactyly, with or without additional features - which can include a wide spectrum of pituitary abnormalities (from asymptomatic to panhypopituitarism), hypothyroidism, microphallus, cryptorchidism and several craniofacial abnormalities, felt to be secondary to disruption of midline development [8].

Alongside with the progressive understanding of the genetic basis of the syndrome, Azzam and colleagues (PH3) justly highlighted the importance of a better characterization of the phenotypic variability of the syndrome, particularly regarding its psychiatric and neuropsychological features, as such a characterization may not only optimize the patient care, as it can contribute to clarify the genetic basis of mental diseases. To date, few studies exist on this topic, the more prominent being the aforementioned, a prospective systematic neuropsychiatry evaluation of 19 subjects with Pallister-Hall Syndrome, which showed no specific characteristic pattern. It must be noted that the small sample size made the analysis of these results difficult to render, which is a consequence of the remarkable rarity of the syndrome. 
However, it must also be noted that such consequence may prove useful as it may provide unique insights into common manifestations of mental disease that are definitively associated with the syndrome, if such a stereotypic pattern can be identified. In the light of this, each additional case report may be useful.

\section{Case Report}

\section{Medical vignette}

Our patient was the second descendant of a consanguinity relationship (the parents are first degree cousins). At the time of birth, the mother was 26 years old, and the father was 32 years old. Both the parents and the first daughter were phenol typically normal. The pregnancy was regularly followed by the GP and uncomplicated, with normal spontaneous vaginal delivery at 38 weeks. There was no known maternal exposure to teratogens of any kind. The new-born weighted $3150 \mathrm{~g}$, length was $49,5 \mathrm{~cm}$ and head circumference was located between P5075. There's register of respiratory distress syndrome in the first hours after birth and a bronchopneumonia, which resolved after a 5 days inward period.

Physical examination of the new-born revealed a characteristic facies, bilateral axial polydactyly, atresia of the left choana and by fid uretra. Posterior examination added the finding of a malformation of the left fibula and bilateral hyperextension of elbow articulations. Chromosomal analysis showed 46X, Y karyotype, with no detectable abnormalities. The physical and psychological development appeared within normality until the age of seven, when the first epileptic seizures occurred (partial complex). EEG findings were compatible with focal epilepsy. At the age of 15 years old the patient was admitted in our psychiatry service for the first time. The clinical records mention symptoms of psychomotor agitation, hetero-aggressiveness and lack of impulse control. At this stage, there's no mention to psychotic symptoms. The inward period lasted for two days, after which the parents signed the informed consent and the patient was dismissed against medical advice, keeping no contact with the mental health services until 2012. At the age of 28 years old, the patient was again admitted, this time presenting with structured persecutory delusions, visual hallucinatory activity, insomnia and hetero-aggressiveness. It was found that there was a history of heavy cannabinoid abuse during the previous years. A CT scan was performed, revealing a hypothalamic hamartoma. Characterization with MRI also showed bilateral hippocampal atrophy. Neurosurgery evaluation excluded electiveness to excision of the tumour. The patients psychotic symptoms remitted after two weeks inward, and he was dismissed with the diagnosis of toxic psychosis, treated with risperidone $9 \mathrm{mg}$ daily, associated with the treatment for the epilepsy, which involved valproic acid $1500 \mathrm{mg}$, topiramate $100 \mathrm{mg}$ and clonazepam $15 \mathrm{mg}$ daily. The genetic study of the mutation involved in the Pallister Hall Syndrome was, at the date of this publication, unavailable. The medical records of our patient also had references to "rare syndrome affecting the finger extensor tendons", which was subjected to surgery, but no more details could be obtained. One record mentions "congenic cardiopathy" with no apparent intervention. The EKG revealed no abnormalities. Regarding the congenital malformation of the right lower limb, there's mention to "significant knee joint instability and tibiotarsal articulation limitation, sequel of congenic fibular hemimelia", treated with orthotic. At the present moment, there is no mention to generalized epileptic crisis, just the partial complex type, with diminished frequency. The neuropsychiatric syndrome seems to be stationary as well, with no residual psychotic symptoms so far.

\section{Neuropsychological Performance}

The neuropsychological evaluation hereby presented was performed in two moments with psychotic symptoms, and 2 months after the resolution of the acute clinical state. We used a battery of tests involving the Portuguese version of the Addenbrooke Cognitive Evaluation Test (Ref), the Auditory Verbal Learning Test (Ref), the Trail Making Test (Ref), Finger Tapping Task (Ref) and the Go/No Go Task. The objective was to evaluate the attention, executive functions, memory, fluency, language, motor speed, processing speed and response inhibition.
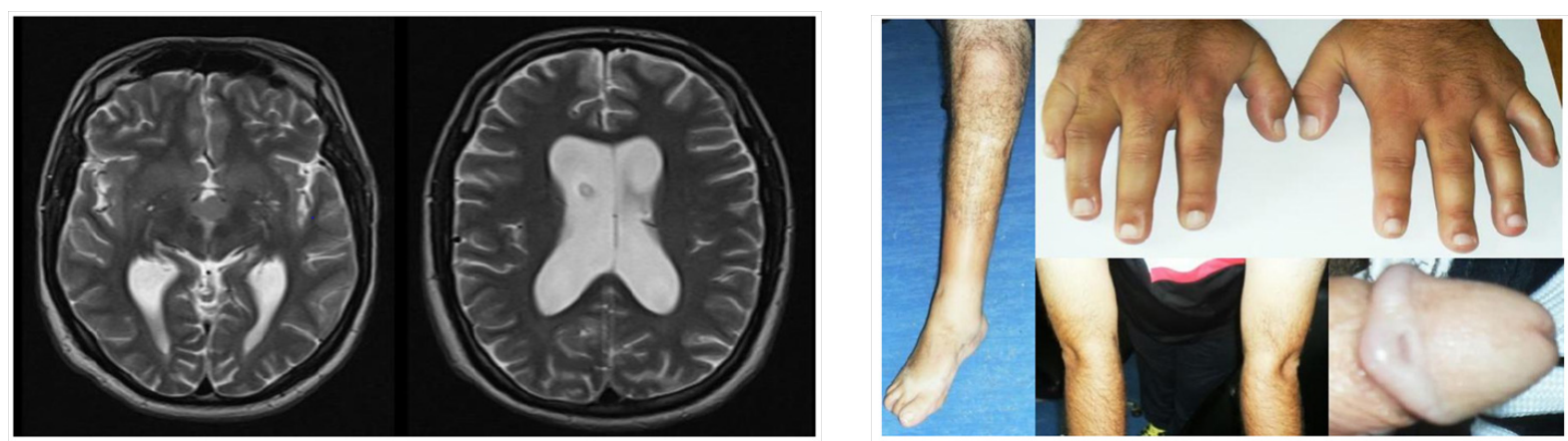

Figure 1: 


\section{International Journal of Cell Science \& Molecular Biology}

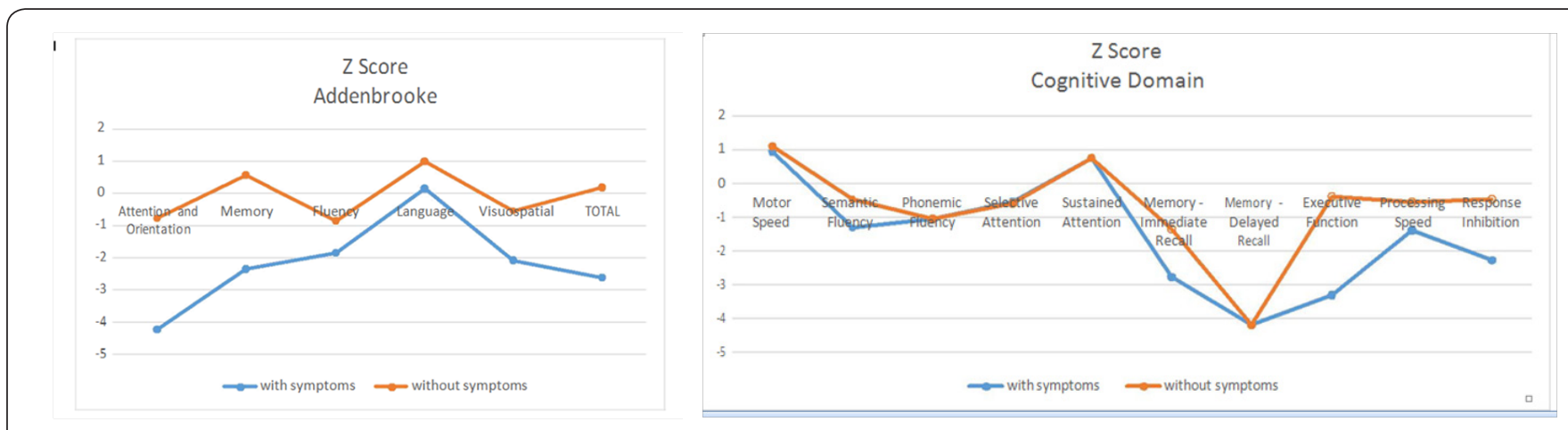

Figure 2:

Our results identified a poor cognitive function (mild cognitive impairment), with significant disability regarding verbal fluency, memory, executive functioning, processing speed and response inhibition. Comparing the two moments evaluated, although the general cognitive profile was similar, there was a better performance in general as evaluated by the Addenbrooke Cognitive Evaluation Test (Figure 1), scoring 85/100 when free of psychotic symptoms, in comparison with a score of 63/100 in the first moment. Regarding the comparison in each cognitive domain (Figure 2), there were differences in the executive function, processing speed and response inhibition, where it was noted a significant improvement when free of psychotic symptoms, being the scores obtain close to those of the general population.

Overall, our result confirm those of previous evaluations of this patient, being the most significant difference a higher impairment in the verbal memory, as evaluated with the Auditory Verbal Learning Test. It should be noted that, considering that our patient presented substantial psychotic features, his cognitive function is atypical, in that he shows close-to-normal performance in areas characteristically affect in such patients - namely at the level of sustained attention and motor speed. It should also be highlighted that our patient, when free of psychotic symptoms, there are significant improvements in the executive functioning and response inhibition, which are particularly important in the management of our case, due to the past history of violent behavior.

\section{Discussion}

Patients with hypothalamic hamartomas are reported to have seizures, particularly brief elastic seizures, refractory to treatment, and behavioural and developmental problems [3-11]. The clinical course of patients with hypothalamic hamartomas associated with Pallister Hall syndrome is less well-known, as most studies focused on isolated hypothalamic hamartomas, and probably included patients with milder forms of Pallister-Hall, eventually confounding the results. Epilepsy foci, particularly of the temporal lobe, are known to be associated with psychosis. In our case study, there is also a history of heavy cannabinoid abuse, which can contribute to the clinical presentation. From a phenomenological point of view, the persecutory nature of the delusional ideation, a delusion-proper, is not incompatible with the clinical picture of a toxic psychosis.

On the other hand, the prominent existence of visual hallucinatory activity is more suggestive of an organic process, and the two features did not always co-occurred in our patient. Overall, it is difficult to attribute symptoms to causes, as our patient has multiple co-occurring events that can act and interact simultaneously as predisposing and precipitating symptoms. Adding to this, the patient has been having an erratic medical care, with long periods regarding which the history of the disorder is not clear. Finally, the quality of the reports in infancy is poor, and much data was probably lost. Nevertheless, this is a rare syndrome with a well-established genetic cause, and so adding reports is the only way to eventually disclose patterns of neuropsychiatric features, a first step towards inter-level analysis.

\section{References}

1. Hall JG, Pallister PD, Clarren SK, Beckwith JB, Wiglesworth FW, et al (1980) Congenital hypothalamic hamartoblastoma, hypopituitarism, imperforate anus, and postaxial polydactyly-a new syndrome? Part I: Clinical, causal, and pathogenetic considerations. Am J Med Genet 7(1): 47-74.

2. Sama A, Mason J, Gibbin K, Young I, Hewitt M (1994) The Pallister-Hall syndrome. Journal of Medical Genetics 31(9): 740-740.

3. Low M, Moringlane JR, Reif J, Barbier D, Beige G, et al. (1995) Polysyndactyly and asymptomatic hypothalamic hamartoma in mother and son: a variant of Pallister-Hall syndrome. Clin Genet 48: 209-212.

4. Grebe TA, Clericuzio C (1996) Autosomal dominant inheritance of hypothalamic hamartoma associated with polysyndactyly: heterogeneity or variable expressivity. Am J Med Genet 66(2): 129137.

5. Unsinn K, Neu N, Krejci A, Posch A, Menardi G, et al. (1995) PallisterHall syndrome and McKusick-Kaufmann syndrome: one entity? J Med Genet 32(2): 125-128.

6. Kang S, Allen J, Graham JM, Grebe T, Clericuzio C, et al. (1997) Linkage mapping and phenotypic analysis of autosomal dominant PallisterHall syndrome. J Med Genet 34: 441-446.

7. Kang S, Graham JM, Olney AH (1997) GLI3 frame shift mutations cause autosomal dominant Pallister-Hall syndrome. Nat Genet 15(3): 266268. 
8. Firmino H, Simoes MR, Pinho S, Cerejeira J, Martins C (2010) Avaliacao Cognitiva de Addenbrooke-Versao Revista (ACE-R) Coimbra.

9. Cavaco S, Pinto C, Goncalves A, Gomes F, Pereira A, etal. (2008) Auditory Verbal Learning Test: Dados normativos dos 21 aos 65 (norms for 2165 years old). Psychologica 49: 208-221.

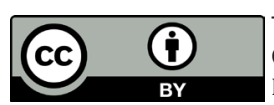

This work is licensed under Creative Commons Attribution 4.0 Licens

DOI: 10.19080/IJCSMB.2017.03.555616
10. Cavaco S, Goncalves A, Pinto C, Almeida E, Gomes F, et al. (2013) Trail Making Test: Regression-based norms for the Portuguese population. Arch Clin Neuropsychol 28(2): 189-98.

11. Moniz M, de Jesus SN, Goncalves E, Viseu J, Pacheco A, et al. (2016b) Portuguese version of Go/NoGo Task: Influence of age in attention and response inhibition reaction time. Psychology 7(2): 254-257.

\section{Your next submission with Juniper Publishers will reach you the below assets}

- Quality Editorial service

- Swift Peer Review

- Reprints availability

- E-prints Service

- Manuscript Podcast for convenient understanding

- Global attainment for your research

- Manuscript accessibility in different formats

( Pdf, E-pub, Full Text, Audio)

- Unceasing customer service

Track the below URL for one-step submission https://juniperpublishers.com/online-submission.php 